\title{
Mid-term outcome of transarterial embolization of renal artery pseudoaneurysm and arteriovenous fistula after partial nephrectomy screened by early postoperative contrast-enhanced CT
}

Satoru Morita ${ }^{1 *}$, Yuka Matsuzaki ${ }^{2}$, Takahiro Yamamoto ${ }^{1}$, Kumi Kamoshida ${ }^{1}$, Hiroshi Yamazaki ${ }^{1}$, Tsuyoshi Tajima ${ }^{3}$, Tsunenori Kondo ${ }^{4}$, Toshio Takagi ${ }^{5}$, Kazuhiko Yoshida ${ }^{5}$, Kazunari Tanabe ${ }^{5}$ and Shuji Sakai ${ }^{1}$

\begin{abstract}
Purpose: To retrospectively evaluate the mid-term outcome of transarterial embolization (TAE) of renal artery pseudoaneurysm (RAP) including arteriovenous fistula (AVF) after partial nephrectomy screened by early postoperative contrast-enhanced CT (CE-CT).

Materials and methods: Eighty-two patients (7.0\%) who underwent TAE after partial nephrectomy were reviewed, from 1166 partial nephrectomies performed over 6 years. In 18 patients (22.0\%), TAE was performed emergently on the median postoperative day (POD) seven. In the remaining patients, elective TAE was performed on the median POD six for RAP detected by early postoperative CE-CT or that emerged on follow-up CE-CT.

Results: In one patient (1.2\%), TAE was performed twice because one of two RAPs could not be embolized during the first TAE, being successfully embolized at the second TAE after readmission with hematuria. Otherwise, no bleeding recurrence or RAPs were observed during the median 1354 follow-up days. Thus, the primary and secondary success rates of TAE were $98.8 \%$ ( 81 of 82 patients) and 100\% (82 of 82 patients), respectively. On angiography, the average number of lesions was $1.7 \pm 0.9$ and the average RAP size was $12.8 \pm 6.0 \mathrm{~mm}$. The shapes of the lesions varied: ovalround 60, oval-round + AVF 36, irregular + AVF 14, AVF 12, irregular 10, disruption 4, and extravasation 3. No major complications were observed. The median inpatient days after TAE were two. No estimated glomerular filtration rate deterioration was observed ( $64.6 \pm 18.6$ vs. $\left.64.2 \pm 18.4 \mathrm{~mL} / \mathrm{min} / 1.73 \mathrm{~m}^{2}, p=0.902\right)$.
\end{abstract}

Conclusion: TAE is largely effective and safe for treating bleedings or RAPs, including AVFs, after partial nephrectomy, as screened by early postoperative CE-CT.

Keywords: Embolization, Renal artery, Pseudoaneurysm, Partial nephrectomy, Computed tomography

\footnotetext{
* Correspondence: i@imodey.com

'Department of Diagnostic Imaging and Nuclear Medicine, Tokyo Women's

Medical University, 8-1, Kawada-cho, Shinjuku-ku, Tokyo 162-8666, Japan

Full list of author information is available at the end of the article
}

\section{Springer Open}

(c) The Author(s). 2020 Open Access This article is licensed under a Creative Commons Attribution 4.0 International License, which permits use, sharing, adaptation, distribution and reproduction in any medium or format, as long as you give appropriate credit to the original author(s) and the source, provide a link to the Creative Commons licence, and indicate if changes were made. The images or other third party material in this article are included in the article's Creative Commons licence, unless indicated otherwise in a credit line to the material. If material is not included in the article's Creative Commons licence and your intended use is not permitted by statutory regulation or exceeds the permitted use, you will need to obtain permission directly from the copyright holder. To view a copy of this licence, visit http://creativecommons.org/licenses/by/4.0/. 


\section{Introduction}

Partial nephrectomy is a standard surgical procedure for small renal tumors to preserve renal function after surgery (Campbell et al. 2009; Ljungberg et al. 2010). Laparoscopic or robot-assisted laparoscopic partial nephrectomy has increasingly been used because of its reduced invasiveness (Yang et al. 2014; Aboumarzouk et al. 2012; Patel et al. 2013). However, studies have reported a higher incidence of hemorrhage after laparoscopic surgery, $1.2 \%$ to $7.5 \%$ (Yang et al. 2014; Netsch et al. 2010; Gill et al. 2007; Montag et al. 2011; Nadu et al. 2009; Takagi et al. 2014; Omae et al. 2015), when compared with that in open partial nephrectomy, $0.4 \%$ to $1.6 \%$ (Netsch et al. 2010; Gill et al. 2007; Albani and Novick 2003; Ghoneim et al. 2011). Renal artery pseudoaneurysm (RAP) formation causes hemorrhage and its presentation is often delayed to approximately 2 weeks after surgery (Montag et al. 2011; Albani and Novick 2003; Ghoneim et al. 2011; Hyams et al. 2011; Cohenpour et al. 2007). It has been shown that the incidence of RAP, $15 \%-20 \%$, is higher than that previously reported, when screening by contrast-enhanced computed tomography (CE-CT) in the early postoperative period (Takagi et al. 2014; Omae et al. 2015). In addition, we show that transarterial embolization (TAE) of RAP detected on early postoperative screening by CE-CT can prevent delayed hemorrhage, which occurred in $4.6 \%-4.7 \%$ of cases without CE-CT screening and in $0.6 \%$ with CE-CT screening and TAE (Morita et al. 2015).

However, it is unknown whether delayed hemorrhage or recurrence of RAP, including arteriovenous fistula (AVF), can occur due to TAE or whether any adverse effects on the renal function can appear over a longer period after TAE. The purpose of this study was to retrospectively evaluate the efficacy and safety of TAE for RAP after partial nephrectomy in a large population of patients with mid-time follow-up who underwent early postoperative screening by CE-CT.

\section{Materials and methods \\ Patients}

This retrospective, single-institution study was approved by the institutional review board of our facility. Written informed consent for the individual patient data used in our analysis was waived because of the retrospective nature of the investigation. Between January 2012 and January 2018, 1168 partial nephrectomies were performed for renal tumors in 1142 patients. Two patients were excluded because of their young age ( $<18$ years). Open, laparoscopic, or robotic partial nephrectomy was performed using the standard techniques previously described (Takagi et al. 2014; Omae et al. 2015; Gill et al. 2002; Rogers et al. 2008). After 1166 partial nephrectomies, 82 patients $(7.0 \%)$ underwent TAE. The clinical characteristics of these patients are summarized in Table 1.

\section{CT examinations}

Scheduled early postoperative CE-CT was performed 25 days after surgery to screen for surgical complications, mainly RAP, in each patient, except for those having renal insufficiency, adverse reactions to contrast materials, or with severe asthma. Postoperative CE-CT was performed using 64-row detector scanners (Aquilion 64; Canon Medical Systems, Otawara, Japan) or 320-row detector scanners (Aquilion One or Aquilion One GENE SIS Edition; Canon Medical Systems). The images were obtained at the following settings: pitch, 0.81-0.83; collimation, $0.5 \mathrm{~mm}$; reconstruction thickness/interval, 1.0 $\mathrm{mm} / 1.0 \mathrm{~mm}$; and $120 \mathrm{kVp}$ with automatic exposure control. The early arterial phase images were obtained by using a bolus-tracking contrast monitoring system after injecting the contrast material for $30 \mathrm{~s}$. The amount of contrast material, $600 \mathrm{mgI} / \mathrm{kg}$ with a maximum of 150 $\mathrm{ml}$ and an injection rate of $5.0 \mathrm{ml} / \mathrm{s}$, depended on body weight and iodine concentration (300, 350, or $370 \mathrm{mgI} /$ ml was used).

\section{Indications for TAE}

The CT images were evaluated by one of two interventional radiologists: S.M and T.T, each with more than 10 years of experience in TAE. Trans-axial images with $1.0 \mathrm{~mm}$ thickness and multiplanar reformation and maximum intensity projection images at any angle of the kidney were evaluated using a viewer (ShadeQuest/ ViewR; Yokogawa Medical Solutions, Tokyo, Japan) with a three-dimensional workstation (Aquarius iNtuition, TeraRecon, Foster City, CA). In emergent cases with symptoms and RAP detected by emergent CE-CT, TAE was performed within 1 day. For RAP detected on CE$\mathrm{CT}$, the treatment strategy was decided according to the protocol described as follows in this paragraph (Morita et al. 2015). In general, TAE was performed within 3 days when an apparent RAP, round and $>5 \mathrm{~mm}$ in diameter, was detected. In some cases, minute, irregular, linear, or faint contrast enhancements, which were difficult to diagnose as RAP, were observed. In these cases, the radiologists judged whether embolization was required. In difficult cases, early follow-up CE-CT was performed 2 to 5 days during hospitalization or 1 to 2 weeks after discharge. If the findings became larger or apparent as RAP, TAE was performed subsequently.

\section{Allocation of patients for TAE}

A flowchart of the method of allocating patients for TAE is shown in Fig. 1. Overall, the median TAE postoperative day (POD) from surgery was six (range, 1414). The median follow-up day after TAE was 1354 
Table 1 Patient characteristics

\begin{tabular}{|c|c|}
\hline $\begin{array}{l}\text { Age, years (median, } \\
\text { range) }\end{array}$ & $61(26-81)$ \\
\hline Sex (Male:Female) & $63: 19$ \\
\hline Partial nephrectomy & $\begin{array}{l}\text { Robotic } 45(54.9 \%) \text {, laparoscopic } 16(19.5 \%) \text {, } \\
\text { open } 21(25.6 \%)\end{array}$ \\
\hline $\begin{array}{l}\text { Maximum diameter of } \\
\text { the tumor }(\mathrm{mm})\end{array}$ & $30.4 \pm 16.0$ \\
\hline Pathological diagnosis ${ }^{\mathrm{a}}$ & $\begin{array}{l}\text { Clear cell RCC } 64 \text { (78.0\%), chromophobe RCC } \\
2(2.4 \%) \text {, papillary RCC } 2(2.4 \%) \text {, } \\
\text { angiomyolipoma } 7(8.5 \%) \text {, oncocytoma } 4 \\
(4.9 \%) \text {, and others } 3(3.7 \%)\end{array}$ \\
\hline \multicolumn{2}{|l|}{ In RCC $(n=68)$} \\
\hline $\begin{array}{l}\text { Pathological tumor } \\
\text { stage }^{b}\end{array}$ & $\begin{array}{l}\text { pT1a } 52 \text { (76.5\%), pT1b } 14 \text { (20.6\%), pT2a } 2 \\
(2.9 \%)\end{array}$ \\
\hline Tumor complexity ${ }^{c}$ & $\begin{array}{l}\text { Low } 29(42.6 \%) \text {, intermediate } 29 \text { (42.6\%), high } \\
10(14.7 \%)\end{array}$ \\
\hline Symptoms before TAE & $\begin{array}{l}\text { Progressive anemia } 24 \text {, severe hematuria } 17 \text {, } \\
\text { decrease in blood pressure } 5 \text {, bleeding from } \\
\text { drainage tube } 5 \text {, severe pain } 3\end{array}$ \\
\hline
\end{tabular}

RCC Renal cell carcinoma, TAE Transarterial embolization. Classified according to the 2016 World Health Organization classifications ${ }^{a}$, 2009 TNM classification $^{b}$, and R. E. N. A. L nephrometry score ${ }^{c}$

(range, 9-3220). TAE was performed emergently in 18 patients (22.0\%) with symptoms as follows: severe hematuria 12, progressive anemia 11, decrease in blood pressure 5 , severe pain 3 , and bleeding from the drainage tube 1 . One patient with renal insufficiency who had a sudden decrease in blood pressure and peritoneal hemorrhage on POD seven underwent TAE after confirming RAP by emergent CE-CT. One patient with renal insufficiency and sudden hematuria after discharge underwent TAE without CE-CT on POD 34. Eight patients underwent TAE after emergent CE-CT. The remaining eight patients underwent TAE after scheduled early CE-CT. In the other 64 patients (78.0\%), elective TAE was performed for RAP that was either detected on early CE-CT or emerged by follow-up CE-CT.

\section{Embolization techniques}

A 4-F sheath was inserted via the right femoral artery. Renal angiography was performed using a 4-F shepherd's hook catheter. The RAP-feeding arteries were selected using microcatheters such as the 1.9-F Carnelian Marvel (Tokai Medical Products, Aichi, Japan) with 2.6-F Masters HF (Asahi Intecc Co., Ltd., Nagoya, Japan), 2.0-F Excelsior 1018 (Boston Scientific, Marlborough, Massachusetts), 2.5-F Renegade (Boston Scientific), or 2.0-F Masters Parkway (Asahi Intecc Co., Ltd). Embolization of the affected arteries was performed using microcoils while preserving the normal renal parenchyma as much as possible. Detachable microcoils, such as the Target coil (Stryker Inc., Tokyo, Japan), Penumbra coil (Penumbra Inc., Alameda, CA, USA) or the Interlocking detachable coil (IDC; Boston Scientific), were mainly used. Pushable coils such as the Tornado coil (Cook Inc., Bloomington, IN, USA) were also used. Gelatin sponges (Serescue; Nippon Kayaku Co., Ltd. Tokyo, Japan) or 1:4 mixtures of n-butyl cyanoacrylate and ethiodized oil (Lipiodol; Guerbet Japan, Tokyo, Japan) were used in some cases. In three cases of high-flow AVF, a balloon catheter (Selecon MP Catheter;

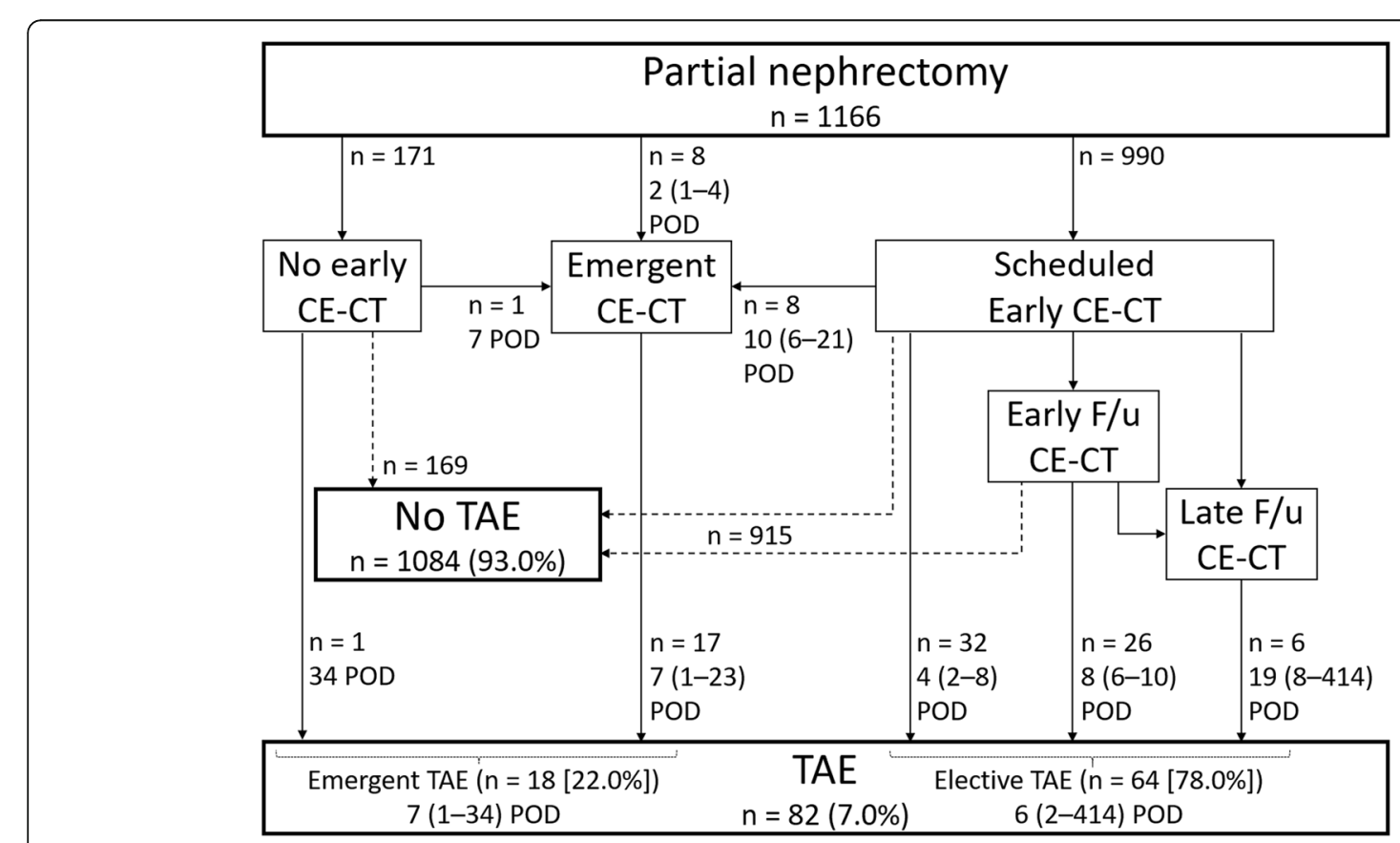

Fig. 1 Flowchart of the allocation of patients for transarterial embolization (TAE). CE-CT = contrast-enhanced CT, POD = postoperative day; median (range), RAP = renal artery pseudoaneurysm, F/u = follow-up 
Terumo, Tokyo, Japan) was used to prevent coil migration into the venous side. The angiographic findings and embolization methods were reviewed in consensus by two interventional radiologists (S.M and H.Y, each with more than 10 years of experience in TAE).

\section{Clinical outcome}

Medical records were reviewed to identify bleeding and complications after TAE using the Society of Interventional Radiology (SIR) classification system for complications by outcome (Sacks et al. 2003). Laboratory data were evaluated, including the estimated glomerular filtration rate (eGFR) recorded pre-surgery, pre- and post(on the day after) TAE, and most recently.

\section{Statistical analysis}

The statistical analyses were performed using JMP 15 software (SAS Institute Inc., Cary, North Carolina). A $P$ value of $<.05$ was considered statistically significant. The changes in eGFR were compared using the Student's t-test.

\section{Results}

In one patient (1.2\%), TAE was performed twice because one of the two RAPs could not be embolized during the first TAE on POD eight but was successfully embolized at the second TAE after readmission with hematuria on POD 22 (Fig. 2). Otherwise, no recurrence of bleeding or RAPs were observed. Thus, the primary and secondary success rates of TAE were $98.8 \%$ ( 81 of 82 patients) and $100 \%$ ( 82 of 82 patients), respectively.

Among the 8 patients with emergent TAE after scheduled early CE-CT, one patient underwent TAE on POD 21 with hematuria for AVFs that were not detected on early CE-CT on POD two (Fig. 3). Apart from this case, early CE-CT showed some findings, as follows: irregular enhancement 5, AVF 1, and a minute RAP of $3 \mathrm{~mm} 1$. A typical case of a developing RAP with symptoms is shown in Fig. 4. Among the 64 patients with elective TAE, one patient underwent TAE for increased AVF, without symptoms, on POD 414 (Fig. 5). In this patient, AVF was suspected on early CE-CT since POD four. However, TAE was not performed on that day. Except for this case, TAE was performed during the postoperative period. The angiographic findings and embolization

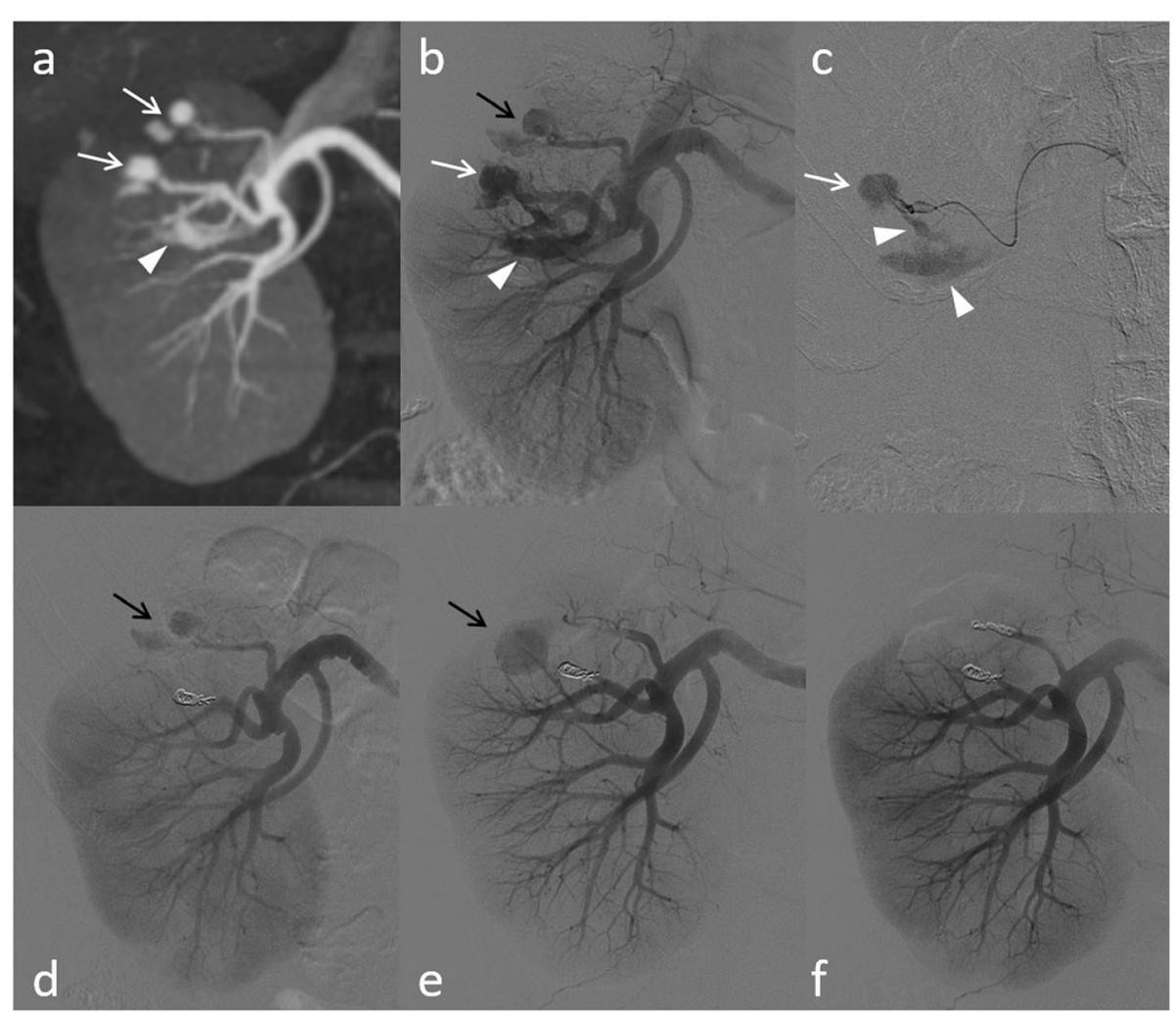

Fig. 2 A case of undergoing transarterial embolization (TAE) twice in a 75-year-old man. a Two renal artery pseudoaneurysms (RAPs) (arrows) with arteriovenous fistula (AVF) (arrowhead) are observed on contrast-enhanced CT on postoperative day (POD) six. b, c, d Although one RAP (white arrows) with AVF (arrowheads) can be embolized using microcoils on POD eight, the other RAP (black arrows) cannot be embolized because of the difficulty of cannulation due to the acute angle of the branch. $\mathbf{e}$, $\mathbf{f}$ The remaining RAP (black arrow), which is increased in size, is successfully embolized using microcoils at the second TAE after readmission with hematuria on POD 22 
methods for RAP including these patients are summarized in Table 2.

The complications after TAE are summarized in Table 3. No major complications were observed. Minor complications were observed in 20 (24.4\%) patients. All of them were mild and disappeared with conservative therapy. All fever was subsequent, after surgery fever. Regarding pain, half of it was back pain due to bed rest after TAE. The median inpatient days after TAE was two (range, $1-14)$. Thirty-nine patients $(47.6 \%)$ were discharged on the day immediately after TAE. The laboratory data are summarized in Table 4. Although the most recent eGFR after surgery was significantly lower than the pre-surgery rate $(p<0.001)$, no deterioration of the eGFR was observed from pre- to post-TAE $(p=0.902)$ or from pre-TAE to the most recent measurement $(p=$ 0.090). No patient required dialysis initiation after surgery or TAE.

\section{Discussion}

We performed CE-CT in the early postoperative period, mainly 2 to 3 days after partial nephrectomy, to screen for RAP. This is done to prevent delayed hemorrhages, which usually occur approximately 2 weeks after surgery, by performing TAE before any ruptures. We show screening by early postoperative CE-CT can detect RAP which contributes to preventing delayed hemorrhage after partial nephrectomy (Morita et al. 2015). In half of the patients who underwent emergent TAE, symptoms presented on median POD two, before obtaining early postoperative CECT during hospitalization. In the other patients, except for one individual with a newly appearing AVF (Fig. 3), some findings, such as irregular enhancement, a minute RAP, and AVF, were observed on early postoperative CECT. Thus, delayed hemorrhage could be expected and TAE was performed smoothly. These factors lead to the successful outcome in which no patient died or had sequela due to bleeding. It is essential to perform less invasive surgeries in laparoscopic or robot-assisted laparoscopic partial nephrectomies.

It is debatable whether early postoperative CE-CTs are required. For the duration of the period analyzed in our study, the procedure was performed in every patient if possible. This is because we did not know the frequency of and risk factors for RAP and, in the dawn of laparoscopic or robotic partial nephrectomy in our institution,

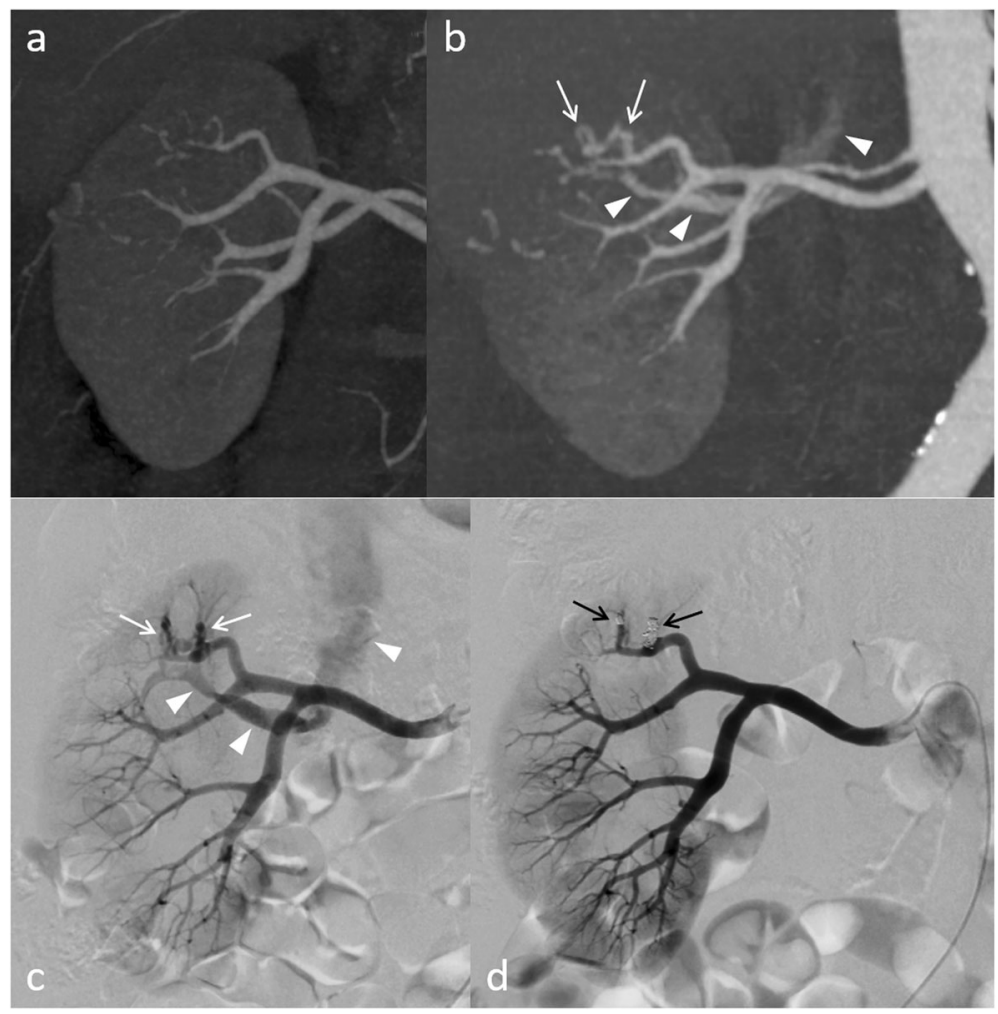

Fig. 3 A case of two newly appearing arteriovenous fistulas (AVFs), with symptoms, in a 67-year-old woman. a No abnormal finding observed on early postoperative contrast-enhanced CT on postoperative day (POD) two. b Two AVFs (arrows) with early venous return (arrowheads) appear on CT obtained on POD 19, with hematuria after discharge. c, d Angiography showing the two AVFs (white arrows) successfully embolized using microcoils (black arrows), with early venous return (arrowheads) disappearing on POD 21 


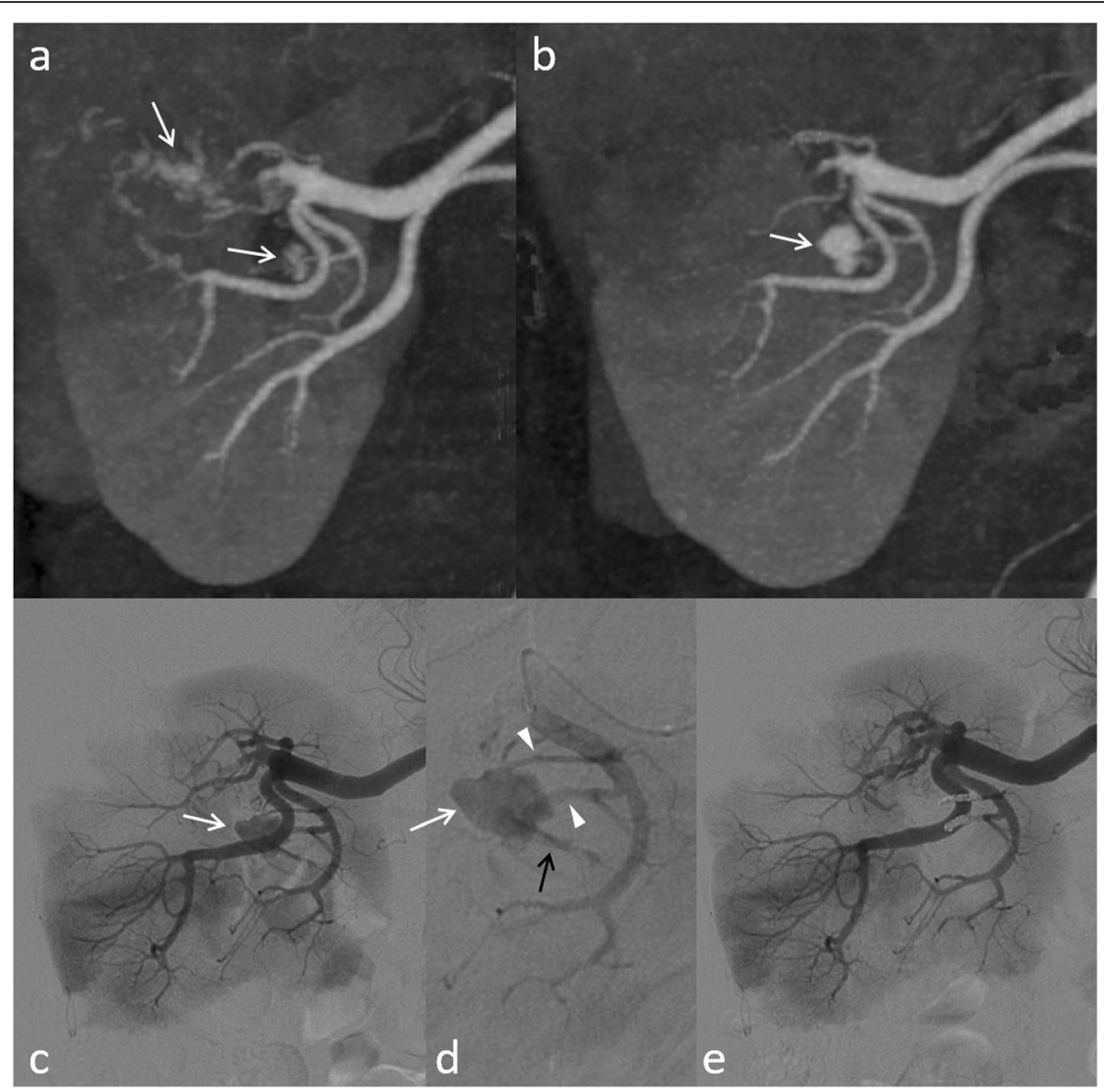

Fig. 4 A case of a developing renal artery pseudoaneurysm (RAP), with symptoms, in a 54-year-old woman. a Irregularly shaped enhancements are observed (arrows) on early postoperative contrast-enhanced CT on postoperative day (POD) three. $\mathbf{b}$ The larger one disappeared and the smaller one increased in size developing into RAP (arrow) on CT on POD seven, with sudden hematuria. $\mathbf{c}$, $\mathbf{d}$, e Angiography shows two branches (arrowheads) that feed the RAP (white arrows) with extravasation into the renal pelvis (black arrow), which are successfully embolized using microcoils on POD eight

we desired to prevent hemorrhagic complications. However, CT radiation exposure and the adverse effects of contrast materials on the renal function in patients with partial nephrectomy are relevant concerns. Recently, we have only been performing early postoperative CE-CT in high-risk cases under the following circumstances: renal sinus exposure surgery, decrease in hemoglobin or blood pressure, or severe hematuria. In addition, we are now largely reducing the contrast material and radiation exposure dose by using a full iterative reconstruction method, a forward-projected model-based iterative reconstruction solution (FIRST; Canon Medical Systems, Otawara, Japan), while improving the visualization of the peripheral renal arteries (Morita et al. 2020). Furthermore, the frequency of RAP in our institution has recently decreased due to improvements in surgical techniques, such as early unclamping, avoidance of deep excision into the renal sinus, and the non-renorrhaphy technique (Omae et al. 2015; Tachibana et al. 2018; Kondo et al. 2015). However, the management of RAPs after partial nephrectomy should be carefully considered, especially in non-high-volume centers, because they can lead to life-threatening complications.

We have illustrated that TAE has no significant adverse effect on renal function. A recent report also showed no deteriorating effect on eGFR in 17 patients who underwent TAE when compared to 34 who did not, at a follow-up of 6 months (Baboudjian et al. 2020). In our study, the eGFR most recently recorded on the median POD 1284 was lower than the pre-surgery one. This is partly natural because the eGFR gradually decreases with age. In addition, the effect of partial nephrectomy is greater than that of TAE. This successful result is due to the development of devices for TAE. In 


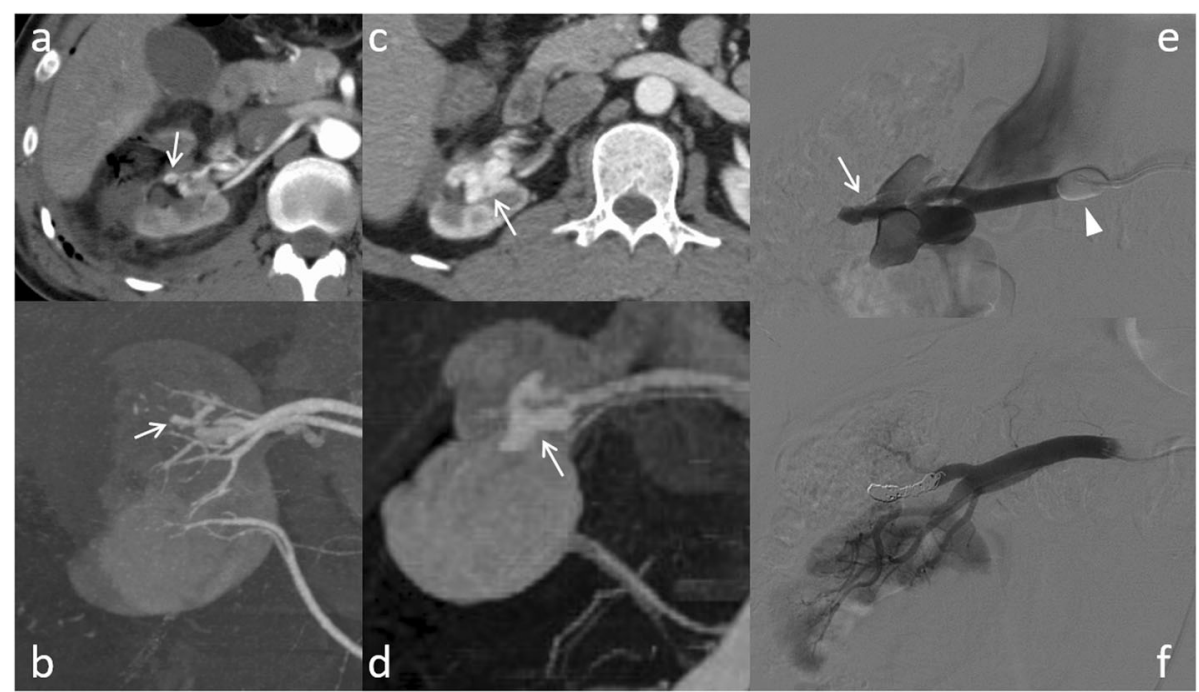

Fig. 5 A case of an increasing arteriovenous fistula (AVF), without symptoms, in a 40-year-old man. a, b Irregularly shaped enhancement (arrows) is suspected on early postoperative contrast-enhanced CT on postoperative day (POD) four. $\mathbf{c}, \mathbf{d}$ It is increased in size and AVF is suspected (arrows) on follow-up CT after 1 year without symptoms. e The AVF (arrow) is embolized using microcoils under balloon occlusion (arrowhead) on POD 414

the kidney, unlike the liver, infarction certainly occurs if normal arteries are embolized. The RAP feeders are mainly the third or more peripheral branches. They are thin and often multiple. Recent detachable microcoils, such as the Target Coil (Stryker Inc.) and the Penumbra Coil (Penumbra Inc), are ideal for embolizing these arteries because the coils are smaller, softer, and easier to position than the older pushable coils. In addition, we prefer to use a triaxial microcatheter system, such as the 1.9-F Carnelian Marvel (Tokai Medical Products),

Table 2 Angiographic findings and embolization methods

\begin{tabular}{|c|c|}
\hline No. of lesions & $1.7 \pm 0.9$ (total 139) \\
\hline Shape of lesions & $\begin{array}{l}\text { Oval-round 60, oval-round + AVF 36, irregular + } \\
\text { AVF } 14 \text {, AVF 12, irregular 10, disruption 4, and } \\
\text { extravasation } 3\end{array}$ \\
\hline Size of RAP (mm) & $12.8 \pm 6.0$ \\
\hline $\begin{array}{l}\text { No. of embolized } \\
\text { branches }\end{array}$ & $2.1 \pm 1.2$ (total 168) \\
\hline $\begin{array}{l}\text { Level of embolized } \\
\text { branches }\end{array}$ & $\begin{array}{l}\text { 1st branch } 0,2 \text { nd branch } 25,3 \text { rd branch or } \\
\text { more } 143\end{array}$ \\
\hline Microcoils & $\begin{array}{l}\text { 4.6 } \pm 3.1 \text { (total } 376 \text { ) } \\
\text { (Target 116, Penumbra 35, GDC 17, Interlock } \\
\text { 145, IDC 4, Tornado 59) }\end{array}$ \\
\hline $\begin{array}{l}\text { Other embolic } \\
\text { materials }\end{array}$ & Gelatin sponge 27, NBCA 6 \\
\hline $\begin{array}{l}\text { Amount of contrast } \\
\text { material }(\mathrm{mL})\end{array}$ & $74.7 \pm 32.4$ \\
\hline
\end{tabular}

AVF Arteriovenous fistula, NBCA n-butyl-2-cyanoacrylate, RAP Renal artery pseudoaneurysm through a high-flow microcatheter. A higher flow rate is required for renal as opposed to liver angiography, especially for patients with AVF. High-flow microcatheters are ideal for obtaining a sufficiently accurate angiography and can support the inner microcatheter during coil embolization (Shimohira et al. 2013). In patients with renal insufficiency, preserving the normal kidney as much as possible and reducing the contrast material dose is crucial for maintaining renal function.

This study had several limitations due to its retrospective nature, with data collected from a single center. First, the study did not have a comparison group, with patients without early postoperative CE-CT and TAE, for example. We cannot know whether TAE is required in patients without symptoms. Over-treatment should be considered. However, it is difficult to not treat RAPs or AVFs if they are apparent. Although in rare cases bleeding due to RAP disappears spontaneously, Hyams et al. reported that the rate of resolution with conservative

Table 3 Complications after TAE

\begin{tabular}{ll}
\hline Major complications & $0(0 \%)$ \\
Minor complications & $20(24.4 \%)$ \\
Back pain (apart from surgical pain) & $8(9.8 \%)$ \\
Fever (more than 3 days) & $8(9.8 \%)$ \\
Vagal reflux & $3(3.7 \%)$ \\
Femoral hematoma & $1(1.2 \%)$ \\
\hline TAE Transarterial embolization &
\end{tabular}

TAE Transarterial embolization 
Table 4 Changes in laboratory data

\begin{tabular}{|c|c|c|c|c|}
\hline & Pre-surgery & Pre-TAE & $\begin{array}{l}\text { Post-TAE } \\
\text { on the next day }\end{array}$ & $\begin{array}{l}\text { Most recent } \\
1284(5-2958) \text { days }\end{array}$ \\
\hline WBC $\left(10^{3} / \mu \mathrm{L}\right)$ & $5761 \pm 1623$ & $7635 \pm 3016$ & $7746 \pm 2269$ & $5308 \pm 1370$ \\
\hline CRP $(\mathrm{mg} / \mathrm{dL})$ & $0.15 \pm 0.31$ & $6.53 \pm 5.12$ & $3.98 \pm 3.75$ & $0.16 \pm 0.26$ \\
\hline $\mathrm{LDH}(\mathrm{U} / \mathrm{L})$ & $181.5 \pm 29.1$ & $285.4 \pm 94.6$ & $277.4 \pm 93.4$ & $186.1 \pm 34.8$ \\
\hline eGFR $\left(\mathrm{mL} / \mathrm{min} / 1.73 \mathrm{~m}^{2}\right)$ & $72.7 \pm 15.7^{*}$ & $64.6 \pm 18.6^{t, \neq}$ & $64.2 \pm 18.4^{\dagger}$ & $60.2 \pm 13.7^{*}, \neq$ \\
\hline
\end{tabular}

TAE Transarterial embolization, WBC White blood cell, CRP C-reactive protein, $L D H$ Lactate dehydrogenase, eGFR Estimated glomerular filtration rate $P$-value $={ }^{*}<0.001,{ }^{\dagger} 0.902$, and ${ }^{\ddagger} 0.090$

management alone was 11\% (Hyams et al. 2011; Darbyshire et al. 2014). Further studies are required to investigate what kind of RAPs or AVFs can in the future be managed with conservative treatment.

\section{Conclusions}

In conclusion, TAE is largely effective and safe for patients with bleeding or RAP, including AVF, screened by early postoperative CE-CT after partial nephrectomy. If embolization was performed adequately, no recurrence of bleeding or adverse effects on the renal function were observed in the mid-term follow-up period. However, AVF should be considered because it can develop infrequently, in a short or long period of time.

\section{Acknowledgements}

NA

\section{Authors' contributions}

SM, YM, TY, KK, HY, TT and SS analyzed and interpreted the patient data including the radiological findings. TK, TT, KY, and $K T$ analyzed and interpreted the patient data including the surgical findings. SM was a major contributor in writing the manuscript. All authors read and approved the final manuscript.

\section{Funding}

The authors declare that they have no funding.

\section{Availability of data and materials}

The datasets used and/or analysed during the current study are available from the corresponding author on reasonable request.

\section{Ethics approval and consent to participate}

This retrospective, single-institution study was approved by the institutional review board of our facility (Tokyo Women's Medical Univeristy Hospital). Written informed consent for the individual patient data used in our analysis was waived because of the retrospective nature of the investigation.

\section{Consent for publication}

Consent for publication was obtained in the form of opt-out on the web-site according to the indication from our institutional review board.

\section{Competing interests}

The authors declare that they have no competing interests.

\section{Author details}

'Department of Diagnostic Imaging and Nuclear Medicine, Tokyo Women's Medical University, 8-1, Kawada-cho, Shinjuku-ku, Tokyo 162-8666, Japan. ${ }^{2}$ School of Medicine, Tokyo Women's Medical University, 8-1, Kawada-cho, Shinjuku-ku, Tokyo 162-8666, Japan. ${ }^{3}$ Department of Radiology, National Center for Global Health and Medicine, 1-21-1, Toyama, Shinjuku-ku, Tokyo 162-8655, Japan. ${ }^{4}$ Department of Urology, Tokyo Women's Medical University Medical Center East, 2-1-10 Nishiogu, Arakawa-ku, Tokyo 116-8567, Japan.
${ }^{5}$ Department of Urology, Tokyo Women's Medical University, 8-1, Kawada-cho, Shinjuku-ku, Tokyo 162-8666, Japan.

Received: 14 August 2020 Accepted: 8 September 2020

Published online: 16 September 2020

\section{References}

Aboumarzouk OM, Stein RJ, Eyraud R et al (2012) Robotic versus laparo-scopic partial nephrectomy: a systematic review and meta-analysis. Eur Urol 62: 1023-1033

Albani JM, Novick AC (2003) Renal artery pseudoaneurysm after partial nephrectomy: three case reports and a literature review. Urology 62(2):227-231

Baboudjian M, Gondran-Tellier B, Abdallah R, Lannes F, Sichez PC, Akiki A, Gaillet S, Toledano H, Delaporte V, Andre M, Karsenty G, Lechevallier E, Rossi D, Vidal $V$, Boissier R, Bastide C (2020) Selective trans-arterial embolization of iatrogenic vascular lesions did not influence the global renal function after partial nephrectomy. Urology 141:108-113

Campbell SC, Novick AC, Belldegrun A et al (2009) Guideline for management of the clinical T1 renal mass. J Urol 182:1271-1279

Cohenpour M, Strauss S, Gottlieb P et al (2007) Pseudoaneurysm of the renal artery following partial nephrectomy: imaging findings and coil embolization. Clin Radiol 62:1104-1109

Darbyshire D, Dukic I, Ali Z, Shackley D (2014) Conservative management of renal artery pseudoaneurysm following partial nephrectomy. Ann R Coll Surg Engl 96(2):e17-e18

Ghoneim TP, Thornton RH, Solomon SB, Adamy A, Favaretto RL, Russo P (2011) Selective arterial embolization for pseudoaneurysms and arteriovenous fistula of renal artery branches following partial nephrectomy. J Urol 185(6):20612065

Gill IS, Desai MM, Kaouk JH et al (2002) Laparoscopic partial nephrectomy for renal tumor: duplicating open surgical techniques. J Urol 167:469-477

Gill IS, Kavoussi LR, Lane BR, Blute ML, Babineau D, Colombo JR Jr, Frank I, Permpongkosol S, Weight CJ, Kaouk JH, Kattan MW, Novick AC (2007) Comparison of 1,800 laparoscopic and open partial nephrectomies for single renal tumors. J Urol 178(1):41-46

Hyams ES, Pierorazio P, Proteek O, Sukumar S, Wagner AA, Mechaber JL, Rogers C, Kavoussi L, Allaf M (2011) latrogenic vascular lesions after minimally invasive partial nephrectomy: a multi-institutional study of clinical and renal functional outcomes. Urology 78(4):820-826

Kondo T, Takagi T, Morita S, Omae K, Hashimoto Y, Kobayashi H, lizuka J, Yoshida K, Fukuda N, Tanabe K (2015) Early unclamping might reduce the risk of renal artery pseudoaneurysm after robot-assisted laparoscopic partial nephrectomy. Int J Urol 22(12):1096-1102

Ljungberg B, Cowan NC, Hanbury DC et al (2010) EAU guidelines on renal cell carcinoma: the 2010 update. Eur Urol 58:398-406

Montag S, Rais-Bahrami S, Seideman CA, Rastinehad AR, Vira MA, Kavoussi LR, Richstone $L$ (2011) Delayed haemorrhage after laparoscopic partial nephrectomy: frequency and angiographic findings. BJU Int 107(9):1460-1466

Morita S, Ogawa Y, Yamamoto T, Kamoshida K, Yamazaki H, Suzuki K, Sakai S, Kunihara M, Takagi T, Tanabe K (2020) Image quality of early postoperative $C T$ angiography with reduced contrast material and radiation dose using model-based iterative reconstruction for screening of renal pseudoaneurysms after partial nephrectomy. Eur J Radiol 124:108853

Morita S, Tajima T, Yamazaki H, Sonoyama Y, Nishina Y, Kenji O, Takagi T, Kondo T, Tanabe K, Sakai S (2015) Early postoperative screening by contrastenhanced $C T$ and prophylactic embolization of detected pseudoaneurysms prevents delayed hemorrhage after partial nephrectomy. J Vasc Interv Radiol 26(7):950-957 
Nadu A, Kleinmann N, Laufer M, Dotan Z, Winkler H, Ramon J (2009) Laparoscopic partial nephrectomy for central tumors: analysis of perioperative outcomes and complications. J Urol 181(1):42-47 discussion 47

Netsch C, Brüning R, Bach T, Gross AJ (2010) Management of renal artery pseudoaneurysm after partial nephrectomy. World J Urol 28(4):519-524

Omae K, Kondo T, Takagi T et al (2015) Renal sinus exposure as an independent factor predicting asymptomatic unruptured pseudoaneurysm formation detected in the early postoperative period after minimally invasive partial nephrectomy. Int J Urol In press; available online January 12

Patel HD, Mullins JK, Pierorazio PM et al (2013) Trends in renal surgery: robotic technology is associated with increased use of partial nephrectomy. J Urol 189:1229-1235

Rogers CG, Singh A, Blatt AM, Linehan WM, Pinto PA (2008) Robotic partial nephrectomy for complex renal tumors: surgical technique. Eur Urol 53:514-521

Sacks D, McClenny TE, Cardella JF, Lewis CA (2003) Society of Interventional Radiology clinical practice guidelines. J Vasc Interv Radiol 14:199-202

Shimohira M, Hashizume T, Suzuki Y, Kurosaka K, Muto M, Kitase M, Mizutani M, Shibamoto Y (2013) Triaxial system for embolization of type II endoleak after endovascular aneurysm repair. J Endovasc Ther 20(2):200-204

Tachibana H, Takagi T, Kondo T, Ishida H, Tanabe K (2018) Comparison of perioperative outcomes with or without renorrhaphy during open partial nephrectomy: a propensity score-matched analysis. Int Braz J Urol 44(3):467-474

Takagi T, Kondo T, Tajima T, Campbell SC, Tanabe K (2014) Enhanced computed tomography after partial nephrectomy in early postoperative period to detect asymptomatic renal artery pseudoaneurysm. Int J Urol 21:880-885

Yang CM, Chung HJ, Huang YH, Lin TP, Lin AT, Chen KK (2014) Standardized analysis of laparoscopic and robotic-assisted partial nephrectomy complications with Clavien classification. J Chin Med Assoc 77(12):637-641

\section{Publisher's Note}

Springer Nature remains neutral with regard to jurisdictional claims in published maps and institutional affiliations.

\section{Submit your manuscript to a SpringerOpen ${ }^{\circ}$ journal and benefit from:}

- Convenient online submission

- Rigorous peer review

- Open access: articles freely available online

High visibility within the field

- Retaining the copyright to your article

Submit your next manuscript at $\boldsymbol{\nabla}$ springeropen.com 